\title{
The effect of undergraduate students on district health services delivery in the Western Cape Province, South Africa
}

\author{
S Reid, ${ }^{1}$ MB ChB, MFamMed, PhD; H Conradie, ${ }^{2}$ MB ChB, MFamMed; D Daniels-Felix, ${ }^{2}$ MA (Psych) \\ ${ }^{1}$ Primary Health Care Directorate, Faculty of Health Sciences, University of Cape Town, South Africa \\ ${ }^{2}$ Ukwanda Centre for Rural Health, Faculty of Medicine and Health Sciences, Stellenbosch University, Cape Town, South Africa
}

Corresponding author: S Reid (steve.reid@uct.ac.za)

\begin{abstract}
Background. The quality of care, attitudes of staff and long-term recruitment of practitioners have been shown internationally to improve health services as a result of a health facility accepting students for teaching. This study aimed to develop further insight regarding the impact of undergraduate student involvement on district health services in South Africa to understand the issues in a resource-constrained environment.

Objectives. To describe the effect of the placement of undergraduate students on service delivery, and to understand the health service and academic factors that influence this effect.

Methods. A descriptive study, using qualitative methods, was undertaken in two rural sites where undergraduate health science students had been recently introduced. Potential respondents were identified to be interviewed on the basis of their positions in the health services, their degree of involvement with students and their knowledge of the health system.

Results. Sixteen participants were interviewed, and described the effect of undergraduate students on service delivery in terms of a balance between the burden and benefit. Three pivotal issues, which could tip the balance in favour of one or the other, included the length of time of student rotations, seniority of the students and number of students allocated to a particular site. Overall, it would appear that the balance was marginally in favour of the benefit of student service delivery.

Conclusion. Undergraduate students can add value to service delivery under certain conditions, but further research is needed to quantify this effect.
\end{abstract}

Afr J Health Professions Educ 2018;10(1):56-60. DOI:10.7196/AJHPE.2018.v10i1.959

A concern of health managers who are focused on service delivery outputs is the effect of the time taken and resources used by teaching undergraduate students on service delivery. The perception exists that the deliberate teaching of students takes time away from immediate patient care, prolongs ward rounds, slows down outpatient queues and uses more medical supplies. Nonetheless, students doing clinical clerkships can potentially add a pair of educated and willing hands as they learn practically by doing rather than being exclusively taught. ${ }^{[1]}$ The balance between what successive groups of students bring to patient care and what they demand from it, is an ongoing tension that must be actively managed across a clinical teaching platform. International best practice and evidence show that over the long term, the health service benefits of hosting students in practices and hospitals outweigh the demands that they place on the system. ${ }^{[2,3]}$ The quality of care, attitudes of staff, and long-term recruitment of practitioners have all been shown to improve health services as a result of a health facility becoming a teaching site in a developed country. ${ }^{[4]}$ However, apart from one Ugandan study regarding community-based education, ${ }^{[5]}$ not much data exist with regard to the effect of students at district level in low- and middle-income countries, where the service pressures are more intense as a result of severely limited resources to deal with an overwhelming burden of disease.

A number of significant developments in health professions education have been initiated in South Africa (SA) over the past decade, in particular the decentralisation of clinical teaching to rural sites ${ }^{[6]}$ and the first yearlong longitudinal placements of medical students in rural district hospitals. ${ }^{[7]}$ District hospitals in SA operate as the second line of medical care in the district health system, with the first level being delivered by clinical nurse practitioners in primary care facilities.

Our study aimed to develop local evidence of the effect of undergraduate student involvement on the processes and outputs of district health services. What factors tip the balance in favour of service delivery, and what factors benefit the students more? Is one of these factors necessarily at the expense of the other, or can they be mutually beneficial? What factors could contribute to this ideal situation? The answers to these questions have important implications for the way that undergraduate student learning on a public health service platform in resource-constrained settings is conceptualised and planned.

These research questions are of equal concern to health service managers as to those in health sciences education; it is therefore difficult to find a single conceptual framework for this study. The starting point for the study could be seen from an educational perspective with implications for curriculum design, in which the theory of service-learning articulated by Dewey ${ }^{[8]}$ and later by Kolb ${ }^{[9]}$ lays equal emphasis on both the service rendered and the experiential learning of the students, with the intention of benefiting equally the provider and the recipient of the services. However, a perspective from management sciences may be more appropriate, in which human resources for health, including students, are one of the many issues that need to be planned, costed, implemented and monitored to keep health services functioning. Borrowing from economics, cost-benefit analysis requires quantitative data that can be costed, but we first need to establish the major issues that have to be compared. This study therefore aimed to 
identify the key issues in assessing the net effect of students on service delivery at district level.

\section{Methods}

A descriptive study was undertaken using qualitative methods to document the process of implementation of undergraduate health science student involvement in three rural sub-districts in the Western Cape Province, SA, and the outcomes with regard to health service delivery. The objectives were to qualify and quantify the effect of undergraduate students on service delivery, and to understand the health service and academic factors that influence this effect.

Rural sites outside metropolitan areas, where undergraduate health science students in medicine, physiotherapy, occupational therapy or speech and language therapy had been introduced up to a year previously, or were about to be introduced into district-level services, were purposively selected after negotiation with a range of stakeholders who relate to each teaching site administered by two different faculties of health sciences. The introduction of successive groups of students into the district-level health services varied at each site, depending on the types of students, their courses and logistics, and ranged from short repeated visits over a period of time to year-long 'longitudinal' placements. ${ }^{[7,10]}$

Ten respondents in the health services were purposively identified by the researchers from each of the two faculties $(N=20)$ to produce an adequate spread of information on the basis of their positions in the health services, their degree of involvement with students and their knowledge of the health system as determined by the researchers.

Potential interviewees were contacted, and after consent was obtained, face-to-face semi-structured qualitative interviews were conducted in English by trained interviewers who were not directly involved in teaching, using a standard interview guide (Appendix 1). Interviews were audio recorded and transcribed verbatim. Additional notes taken by the interviewers were included in the data. Ethical approval for the study was obtained from the University of Cape Town Human Research Ethics Committee (ref. no. 453/2011), and permission was obtained from the Western Cape Government to conduct the study in its facilities. Analysis of the data was carried out independently by two researchers using an inductive approach to code major and minor themes according to the framework method, ${ }^{[11]}$ then debating and discussing differences of interpretation and emphasis before deciding on the final codes, as well as their inter-relationships.

\section{Results}

During a period of 9 months in 2012, 7 participants were interviewed at one site and 9 at another site. These included 2 district managers, 2 hospital chief executive officers (CEOs), 1 operational manager, 3 medical managers, 2 family physicians, 3 hospital clinicians and 3 primary healthcare managers. Four potential respondents were not available at the time of the interviewers' visits. Participants talked freely and interviews lasted between 30 and 60 minutes.

The experience of accommodating undergraduate students on the service platform was described in terms of two opposing forces, i.e. the burden on and the benefit to service delivery. These were contributed to respectively by a number of different factors, which are described in more detail below. Three fundamental issues could tip the balance in favour of burden or benefit, as they determined the overall effect more substantially (Fig. 1). These 'fulcrum' issues were pivotal, and included the length of time of the

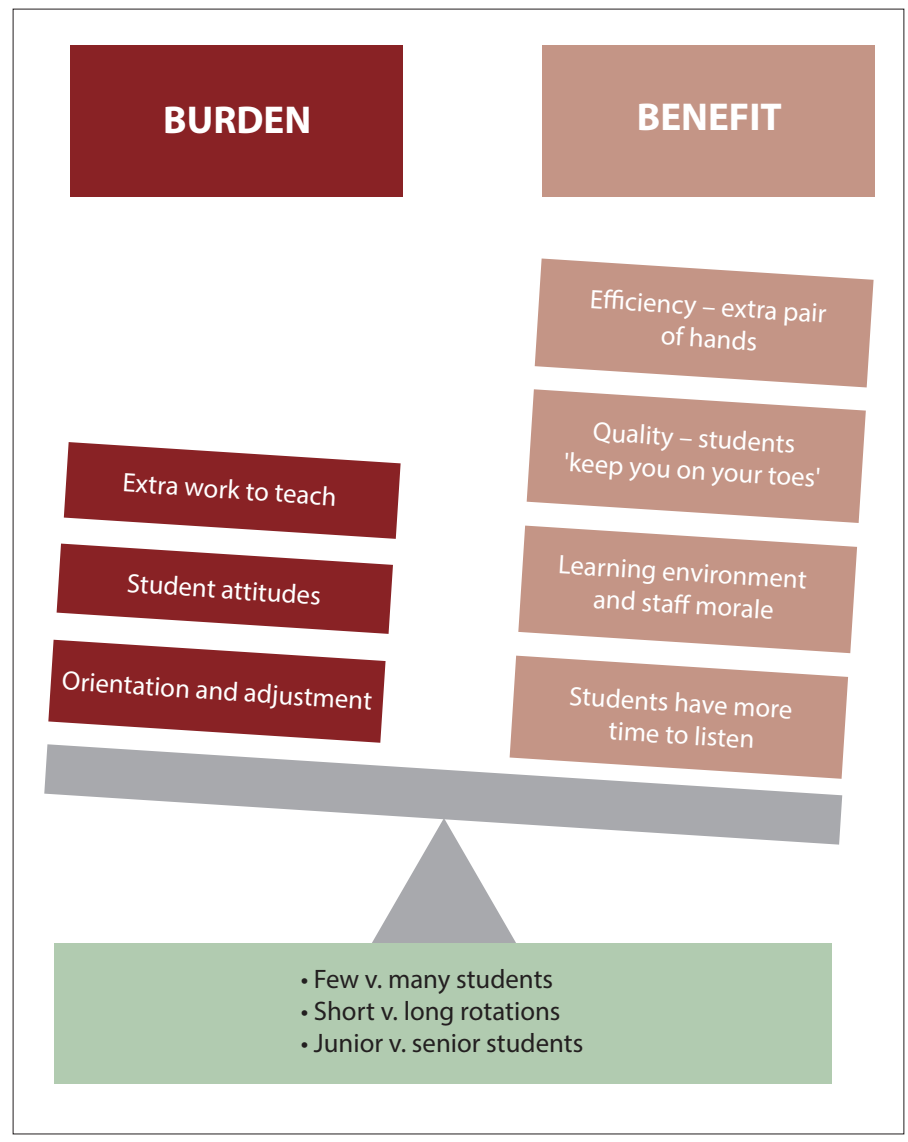

Fig. 1. A diagrammatic representation of the major themes.

student rotations, the seniority of the students and the number of students allocated to a particular site.

Overall, taking all the data into account, the balance was assessed as marginally in favour of the benefit to service delivery of students on the platform, as directly articulated by two respondents:

'They were also I would say more helpful than they were [a burden] or they saved us more time than they took time.' (Family physician)

'... they help us much more than they are a drawback.' (Medical manager)

\section{Fulcrum issues}

\section{Short v. long rotations}

Respondents clearly favoured longer student rotations:

'The longer period that the students are placed here permanently, obviously is more beneficial for the different departments, they become part of the team and work as part of the team, whereas the small, the 2-week and 10-day rotations, they don't have the time to become part of the team ... So I prefer, and I think my departmental heads prefer the longer rotations here.' (District manager)

'But I think if they stay for a good while then it will have an impact, then they become useful as you've orientated them.' (Family physician)

'I think after 2 - 4 weeks they start adding to the service.' (Family physician)

\section{Junior v. senior students}

Senior students were preferred over juniors:

'They are final years, so they know a lot and have practical experience. 
They are far progressed from the junior grades, so they are very helpful. In that sense I would say they help us much more than they are a drawback.' (Medical manager)

'It's been nicer with the say fifth-, sixth-year students. The fourth-year students tend to be, their knowledge is a bit less, so they tend to take more of your time to teach them, but it's been positive so far.' (Hospital clinician)

\section{Number of students}

A number of respondents made it clear that large numbers of students could overwhelm the clinicians, and reasonable limits need to be set on the maximum number of students at any one time at each health facility. The fewer the number of students, the more individual attention they would receive, and therefore the more responsibility they could take clinically under direct supervision. Large groups are difficult to co-ordinate, and they require dedicated management:

'I think a critical mass is important - how many students per consultant or per department, and I know the university has mentioned or has got maybe bigger plans of the numbers and I have been ... approached by the head of department at the tertiary institute to say well I want to send you more students, but we don't have space. I just had to point blankly refuse, although I love to do it. I have mentioned that the time spent with them, it won't be the same quality of time that we have seen up to now. So there is a critical mass which we will have to protect and ... I am very hesitant to say that any student ... more than three at a time in a department of our size will be positively affected, I think it will kind of, that's about the limit we can handle.' (Hospital clinician)

\section{The burden of teaching}

The extra work involved in teaching was described as follows:

'... they help them and teach them but in the end it is my job to make sure they do their tasks, so that takes a lot of time.' (Family physician)

'... you feel responsible for them, so that in a sense it's extra work ... . (Family physician)

In terms of understanding the burden of students on service delivery, there were three major themes that emerged from the interviews: the extra time involved in teaching, the orientation of new groups of students and negative student attitudes. Two minor themes also became apparent: students' different learning styles and university demands.

\section{The time for teaching}

It is clear that students involve extra time, as explained by numerous respondents:

'You have to think a bit more and explain more, so I think that is the biggest impact. It obviously takes extra time because you have to speak now, you can't think of something, but I think that is the biggest impact by far.' (Family physician)

'It does mean you must go a bit slower because you must explain to the students, you must orientate them, you must tell them you see a patient there, I'll see a patient here. You must go slowly around this, you must explain to them or they must present to you.' (Family physician)

'It just takes longer to do everything if you have students with you because you can't just expect them to follow you around and absorb things. So when you have students with you, unless you ignore them, all of your activities do take a little bit longer.' (Hospital clinician)

\section{Orientation and adjustment}

The initial period of orientation of new groups of students takes its own time: '... with any new project there is an adjustment phase and I think the irony, I mean it is the same period when the junior doctors, the community-service doctors also start. So the whole team could perceive or feel the burden of having more inexperienced team members, but as the year progresses the other doctors also catch on and the students become more and more confident.' (Family physician)

'I think the first day or two you have to show them where everything is, but once they are settled in, and that's just a couple of days, then they are part of the team and they help a lot.' (Family physician)

\section{Student attitudes}

Some of the students were perceived to have negative attitudes, or did not show enthusiasm:

'We've had many like that who are not disciplined, they duck and dive, who you have to watch because it's one thing I definitely don't care about students, if they're not there, I say to them they must start at 7:30, if you're not there I'm not looking for you, but I'm not going report then that you're gone.' (Medical manager)

'... not the SIs [student interns], I think they were fourth years or fifth years, some of them come here with an attitude, I just want to observe like in [tertiary hospital]. I know they are not here to work but sometimes you learn more if they do the thing physically themselves, but they don't want to, they just want to observe.' (Primary healthcare manager)

\section{Students differ}

Furthermore, students vary, and some struggle with self-directed learning styles: 'I can just imagine if it is a student that isn't really equipped for this kind of situation, where they need to do self-study. There is absolutely no way I will be able to supervise them and you know push them to every exam. (Family physician)

'Some students come here with a lot of confidence, but they are more work than they save us time... ? (Primary healthcare manager)

\section{University workshops take up time}

The demands of the university were mentioned by one participant:

'One of the things that I find quite difficult is that we are quite often asked to attend workshops and so on by the university and I think that they actually don't realise how pushed we are for time to get through the clinical work and so it is the sort of peripheral activities ... from the university are also a significant use of time.' (Hospital clinician)

\section{Benefits}

The benefits to service delivery of hosting students are summarised in four major themes: efficiency, quality of care, a learning environment and thoroughness. Three minor themes were also identified: teamwork, community involvement and rural career choices.

\section{Efficiency - an extra pair of hands}

Students are often regarded as part of the workforce: 
'... but having students for me I can say it is like having an extra pair of hands.' (Operational manager)

'... it makes the flow of patients and the work lighter because they come in the mornings, they help with ward work, see patients and then present patients.' (Medical manager)

'They basically just have to work with us and I mean that is just a boon for us.' (Family physician)

'So you usually don't have to from scratch work through the patients yourself, you can just have a quick look and decide whether you're going that way or whatever. So they save a lot of time seeing patients that you don't have to repeat.' (Medical manager)

\section{Quality of care - students 'keep you on your toes'}

The students retained the respondents' interests in their field of expertise by challenging their thoughts:

'You have to verbalise what you are doing and thinking, and that sometimes forces you to think a bit more because you have to explain it to a student.' (Medical manager)

'Keep you on your toes, yes, that is what they really do, they keep you on your toes.' (Medical manager)

'The doctors they are also now more alert.' (Medical manager)

'... it keeps me challenged; I have to organise my thoughts.' (Hospital clinician) 'When I have to suddenly take a history and examine a patient with a student around, that, terrible to admit it, but my professionalism doubles.' (Family physician)

\section{Learning environment and staff morale}

The teaching and learning environment had a positive effect on staff morale: 'The clinicians have to know what they are talking about because the students ask questions and they have got to know. So I think in general it uplifts the, shall I say, the knowledge base of the clinicians working in the hospital and it is good, it stimulates a type of a learning environment.' (District manager)

'So you are seeing in the same system, in-service training and student teaching. It must be integrated. [They are] not separate systems, you're talking about one health system that has a teaching/learning component that can include students, not as separate entities but as part of the same thing.' (Family physician)

\section{Students have more time to listen and be thorough}

'It is more efficient and quicker because they are more thorough, they work thoroughly, because they are learning they usually do it in order as it is supposed to be done.' (Primary healthcare manager)

'She had time to talk to this patient and she sat and she actually had a long discussion with her ... if I say that quality could maybe come into it because students have more time, they're not that pressurised to work through these patients quickly.' (District manager)

'... one student picked up a congenital anomaly on a baby ... a newborn baby ... that would have been missed if it wasn't seen by one of the doctors.' (Family physician)

\section{Teamwork}

'... it's just one day you have to take time and show them everything and then they are part of the team, they are working with us ... ?' (Medical manager)
'... so they get to be part of that clinical environment and I think also the community will then recognise them as being part of the team.' (Family physician)

'... whereby for us as nurses or for the whole team to function or to be functional is not a one-man show, it's a team effort. So for them being around with us, or for them being here, it makes our workload easier or lighter.' (Primary healthcare manager)

\section{Community engagement}

Students are involved in community projects that contribute to service delivery indirectly by focusing on prevention and health promotion:

' $J a$, ja they are involved with the community, whereby they initiate some projects. We have a project [in the] black community around here, whereby they have initiated the support groups; they run for the chronic patients whereby really if I walk around town they will be telling me that okay things are going well in the community because of their initiatives. (Operational manager)

\section{Rural career choices}

The long-term goal of attracting students to rural practice after they have graduated was articulated clearly:

'... those situations and when they realise it is actually a very fulfilling job and they might, you know, go and work rural themselves.' (Medical manager) '... and hopefully if it is part of the experience, they would choose to stay in the public sector, in a more rural setting.' (Family physician)

\section{Discussion}

This study has outlined a number of key issues with regard to the effect of undergraduate students on district health services in SA. The major themes, as outlined in Fig. 1, give a snapshot of the balance in favour of a positive effect, depending on certain pivotal issues. It is clear from the data that the situation differs widely between different perspectives and sites, but the overall qualitative result is more in terms of benefit than burden, which is in accordance with the literature from other countries. ${ }^{[3,12,13]}$ It could be argued that the burden and the benefit are not mutually exclusive categories, as every output requires some form of input. Furthermore, the factors contributing to either the burden or the benefit are not additive, as this was not a quantitative study. It would seem difficult to reduce all the major themes in these results to numbers, as the model in Fig. 1 might suggest, e.g. it is difficult to quantify, let alone directly compare, the general effect on staff morale and the stimulation of a learning environment against a factor such as the variety of student attitudes to learning. It was surprising how little attention was given to the eventual career choices of students, as this is one of the key motivations for initiating rural education platforms, but most of the respondents seemed to be more concerned with the immediate pressures of services rather than longer-term problems. ${ }^{[14-16]}$

Nevertheless, the pivotal issues of the length of rotations, seniority of students and number of students at each site are quantifiable, and are clearly within the direct control of the faculties that send the students out; therefore, in the programme design, this balance can be actively negotiated and managed ${ }^{[17]}$ Some of the factors, such as the time required for teaching, could possibly be measured directly. The question of what length of time of a student rotation in a given health facility is enough to tip the balance in favour of service delivery, is indicated by some of the following results, 
e.g. one of the respondents mentioned that after the first ' 2 - 4' weeks of orientation, final-year students start contributing to service delivery. This question of 'How long is enough?' deserves further research, preferably of a quantitative nature, as Worley and Kitto ${ }^{[18]}$ have suggested that a hypothetical 'turning point' lies somewhere between 4 weeks and 5 months. While such a quantification has obvious pragmatic implications for curriculum design, it would align equally with a theoretical framing in terms of management sciences and educational theory, as it would enable student teaching to be accounted for in terms of its cost. As tertiary education generally becomes more managerial in its approach, this is an inevitable factor to consider in health professions education.

\section{Study limitations}

The limitations of the study include the small number of sites and respondents, but the inclusion of sites run by two different faculties contributes to the validity of the findings through triangulation: the data from the two sources were remarkably similar. The researchers, as academics from the faculties involved, recognised their bias in favour of the benefit of students to service delivery, and attempted to minimise this by recursive discussion of the data itself, staying close to what the respondents said. Similarly, the potential bias introduced by interviewers was counteracted by using a number of trained interviewers at different sites.

\section{Conclusion}

Undergraduate students can add benefit to health services if health professions educators plan their clinical rotations, recognising the pressures under which their clinical supervisors work to deliver services to patients. We recommend that health service managers and health professions educators collaborate closely and continually to optimise the benefit of hosting students on the district health platform for educational as well as service outcomes.

Acknowledgements. This project was undertaken by the Collaboration for Health Equity through Education and Research (CHEER). The authors thank the interviewers and all the interviewees for their contributions to the study. Author contributions. SR and HC conceptualised the study together with members of CHEER, and DD-F collated the data. All three authors analysed the data, and SR drafted the manuscript, which all authors reviewed.

Funding. The study was funded through a grant from Atlantic Philanthropies. Conflicts of interest. None.

\footnotetext{
1. Kirz HL, Larsen C. Costs and benefits of medical student training to a health maintenance organization. JAMA 1986;256(6):734-739. https://doi.org/10.1001/jama.256.6.734

2. Walters L, Worley P, Prideaux D, Lange K. Do consultations in rural general practice take more time when practitioners are precepting medical students? Med Educ 2008;42(1):69-73. https://doi.org/10.1111/.13652923.2007.02949.x
}

3. Price R, Spencer I, Walker I. Does the presence of medical students affect quality in general practice consultations? Med Educ 2008;42(4):374-381. https://doi.org/10.1111/j.1365-2923.2008.03016.x

4. O'Flynn N, Spencer J, Jones R. Does teaching during a general practice consultation affect patient care? Br J Gen Pract 1999;49(438):7-9.

5. Atuyambe LM, Baingana RK, Kibira SPS, et al. Undergraduate students' contributions to health service delivery through community-based education: A qualitative study by the MESAU Consortium in Uganda. BMC Med Educ 2016;16(1):123. https://doi.org/10.1186/s12909-016-0626-0

6. Van Schalkwyk SC, Bezuidenhout J, Conradie HH, et al. 'Going rural': Driving change through a rural medica education innovation. Rural Remote Health 2014;14:2493. https://doi.org/10.3109/0142159x.2012.719652

7. Voss M, Coetzee JF, Conradie H, van Schalkwyk SC. 'We have to flap our wings or fall to the ground': The experiences of medical students on a longitudinal integrated clinical model. Afr J Health Professions Educ 2015;7(Suppl 1):119-124. https://doi.org/10.7196/AJHPE.507

8. Kraft R. Service learning Educ Urban Soc 1996-28(2):131-159. https///doi.org/10.1177/0013124596028002001 9. Kolb DA. Experiential Learning: Experience as the Source of Learning and Development. Englewood Cliffs, NJ Prentice Hall, 1984.

10. Hudson JN, Poncelet AN, Weston KM, Jushnell JA, Farmer EA. Longitudinal integrated clerkships. Med Teach 2016;39(1):7-13. https://doi.org/10.1080/0142159x.2017.1245855

11. Gale NK, Heath G, Cameron E, Rashid S, Redwood S. Using the framework method for the analysis of qualitative Gale NK, Heath G, Cameron E, Rashid S, Redwood S. Using the framework method for the analysis of qualitative
data in multi-disciplinary health research. BMC Med Res Methodol 2013;13:117. https://doi.org/10.1186/14712288-13-117

2. Walters L, Prideaux D, Worley P, Greenhill J, Rolfe $\mathrm{H}$. What do general practitioners do differently when consulting with a medical student? Med Educ 2009;43(3):268-273. https://doi.org/10.1111/j.1365-2923.2008.03276.x

13. Coleman K, Murray E. Patients' views and feelings on the community-based teaching of undergraduate medical students: A qualitative study. Fam Pract 2002;19(2):183-188. https://doi.org/10.1093/fampra/19.2.183

14. Mathers J, Parry J, Lewis S, Greenfield S. What impact will an increased number of teaching general practices have on patients, doctors and medical students? Med Educ 2004;38(12):1219-1228. https://doi.org/10.1111/ j.1365-2929.2004.02014.x

15. Benson J, Quince T, Hibble A, Fanshawe T, Emery J. Impact on patients of expanded, general practice based, student teaching: Observational and quantitative study. BMJ 2005;331(7508):89. https://doi.org/10.1136/ bmi. $38492.599606 .8 \mathrm{~F}$

16. Blitz J, Bezuidenhout J, Conradie H, de Villiers M, van Schalkwyk S. 'I felt colonised': Emerging clinical teacher on a new rural teaching platform. Rural Remote Health 2014;14:2511.

17. Wachter RM, Katz P, Showstack J, Bindman A. Reorganizing an academic medical service: Impact on cost, quality patient satisfaction, and education. JAMA 1998;279(19):1560-1565. https://doi.org/10.1001/jama.279.19.1560 18. Worley PS, Kitto P. A hypothetical model of the financial impact of student attachments on rural general practices. Rural Remote Health 2001;1(1):83

Accepted 15 September 2017

\begin{tabular}{|c|c|}
\hline 1. & $\begin{array}{l}\text { Please tell me about your experience of undergraduate health } \\
\text { science students in this sub-district. }\end{array}$ \\
\hline 2. & $\begin{array}{l}\text { In your opinion, what is/will be/has been the impact of having } \\
\text { students in this sub-district on the health services? }\end{array}$ \\
\hline 3. & Is it overall a positive effect, or a negative one? \\
\hline 4. & Why? Can you explain your opinion? Can you give examples? \\
\hline 5. & $\begin{array}{l}\text { What do you think is the effect of having students here on: } \\
\text { Human resources in the sub-district? } \\
\text { Quality of care in the sub-district? } \\
\text { Finances in the sub-district? } \\
\text { Morale and motivation of health personnel? }\end{array}$ \\
\hline 6. & $\begin{array}{l}\text { In your opinion, has there been any change in any of these } \\
\text { aspects since students started coming here? (Note: in second } \\
\text { round, refer back to first-round transcripts) }\end{array}$ \\
\hline 7. & How could any of these changes be measured and quantified? \\
\hline 8. & $\begin{array}{l}\text { What documents or statistics could be used to track such } \\
\text { changes? }\end{array}$ \\
\hline
\end{tabular}

